\title{
Description of the immature stages of Syritta flaviventris (Diptera: Syrphidae) and new data about the life history of European species of Syritta on Opuntia maxima
}

\author{
Celeste PÉREZ-BAÑóN and M. Angeles MARCOS-GARCÍA \\ Departamento de Ciencias Ambientales y Recursos Naturales, Universidad de Alicante, E-03080 Alicante, Spain; \\ e-mail: celeste@carn.ua.es
}

Key words. Syrphidae, Syritta flaviventris, Syritta pipiens, immature stages, morphology, feeding behaviour, Opuntia maxima, Spain

\begin{abstract}
Adults of Syritta flaviventris and S. pipens were reared from larvae collected on decaying platyclades of Opuntia maxima Miller (Cactaceae) from the Spanish Mediterranean coast. The larva and puparium of S. flaviventris, as well as preliminary data about its life cycle are described. The feeding behaviour of the larva in relation to the cephalopharyngeal skeleton morphology is analysed. Based on the present data, a comparative table containing the main morphological characteristics of the immature stages of European species of the genus Syritta is presented.
\end{abstract}

\section{INTRODUCTION}

The genus Syritta comprises 23 species, of which 1 is present only in the Palaearctic region, 12 in the Afrotropical region, 5 in the Australasian and Oceanian regions, and other 5 species are widespread (Thompson et al., 1976; Thompson \& Vockeroth, 1989; Peck, 1988; Dirickx, 1994, 1998). In Europe only S. flaviventris Macquart, 1842 and S. pipiens (L., 1758) have been found, the latter being one of the most common and ubiquitous hoverflies whose larvae do not feed on aphids (Gilbert, 1993). The geographical distribution of $S$. pipiens is $\mathrm{Pa}-$ laearctic (widespread in Europe), Nearctic and Oriental. On the other hand $S$. flaviventris is known from the Mediterranean Basin and the Oriental, Neotropical and Afrotropical regions. In Europe the circum-mediterranean area is the only territory where these species are sympatric.

Although species of Syritta are common and widespread, they are biologically poorly known. Within the genus Syritta, only the immature stages and life history of S. pipiens have been described (Krüger, 1926; Hodson, 1931; Heiss, 1938; Dixon, 1960; Hartley, 1961). The rearing records indicate that the larva of $S$. pipiens is saprophagous, occurring in various kinds of decaying matter including garden compost heaps, silage and manure but not in ponds or pools (Lunbeck, 1916; Gilbert, 1993; Rotheray, 1993). Information about the habits, biology and ecology of $S$. flaviventris is virtually lacking.

Prickly pear cacti (Opuntia spp.) were deliberately introduced into Europe in the 16th century from the New World. In several Mediterranean countries, certain species escaped from cultivation and became naturalized plants and in some cases are serious agricultural pests (Dodd, 1940). In the New World decaying platyclades (i.e. the stems) have been found to be the larval breeding medium of several saprophagous syrphid species, mainly in the genus Copestylum Macquart, 1846 (Bugbee \& Rei- gel, 1945; Ryckman \& Ames, 1953; Telford, 1973; Wallace \& Lavallee, 1973; Maldonado Capriles \& Berrios, 1977; Maier, 1982). In the Mediterranean area, at least two saprophagous species of Syrphidae, Eumerus purpurariae Baez, 1982 and Syritta pipens, have been found to develop in decaying platyclades of Opuntia maxima Miller (= O. ficus-indica auct.) (Pérez-Bañón \& MarcosGarcía, 1998). In this paper we present a third species, $S$. flaviventris, whose larvae also breed in decaying platyclades of $O$. maxima.

The objectives of the present study are: (1) to describe the larva (L3) and puparium of $S$. flaviventris, (2) to distinguish between the immature stages of the two European Syritta species, (3) to relate feeding behaviour to the morphology of the cephalopharyngeal skeleton, and (4) to present rearing data for $S$. pipiens and S. flaviventris.

\section{MATERIAL AND METHODS}

Two adults of $S$. flaviventris and approximately seventy of $S$. pipens were reared from larvae collected on the cactus Opuntia maxima at Cabo de las Huertas $\left(38^{\circ} 21^{\prime} 20^{\prime \prime} \mathrm{N}, 0^{\circ} 24^{\prime} 12^{\prime \prime} \mathrm{W}\right.$; UTM grid: 30SYH2648) and on Nueva Tabarca $\left(38^{\circ} 9^{\prime} 57^{\prime \prime} \mathrm{N}\right.$, $0^{\circ} 28^{\prime 2}$ "W; UTM grid: 30SYH2027, 30SYH2127), a small Mediterranean island ( $43 \mathrm{ha}$ ) $5 \mathrm{~km}$ off the coast. Both places are in Alicante province (south-eastern Spain).

Rearing took place in a growth chamber at $16-22^{\circ} \mathrm{C}, 80 \pm 5 \%$ r. h. with a constant photo-regime of $15 \mathrm{~L}: 9 \mathrm{D}$ photoperiod. Plastic cages ( $43 \mathrm{~cm}$ wide, $24 \mathrm{~cm}$ deep, $26 \mathrm{~cm}$ high) containing decaying platyclades of $O$. maxima were checked daily and the L3 instars were kept in a cylindrical plastic cage $(40 \mathrm{~mm}$ high, $80 \mathrm{~mm}$ wide) together with small pieces of dry platyclades to facilitate pupation. Puparia were placed individually in $55 \mathrm{~mm}$ diameter dishes and inspected daily until the emergence of the adults.

Larvae selected for preservation were L3 instars. Typically, the larvae of this instar have two discs of differentiated cuticle on the dorsal surface of the first abdominal segment. For permanent preservation, larvae were killed by immersion in cold water 


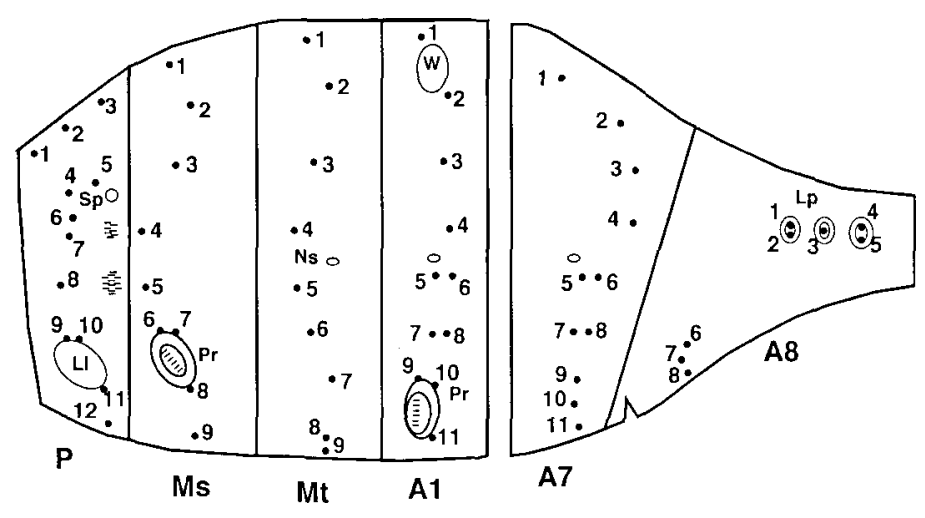

Fig. I. Map of the chaetotaxy of the third instar larva of S. flaviventris showing the positions of the sensilla group on: $\mathrm{P}-$ prothorax; Ms - mesothorax; Mt - metathorax; A1, A7 - first and seventh abdominal segments; A8 - anal segment (hind end); Ns nonfunctional spiracle; $\mathrm{Ll}$ - lateral lip; $\mathrm{Pr}$ - proleg; $\mathrm{Sp}$ - anterior functional spiracle; $\mathrm{W}$ - area of differentiated cuticle through which the pupal spiracle will be thrust.

and boiled slowly for about four minutes to extend them. Afterwards, they were preserved in $70 \%$ alcohol.

The external morphology of the third instar larva of S. pipiens and $S$. flaviventris was compared segment by segment. Descriptions are based on preserved specimens with larval characters checked against living specimens in order to minimise errors due to preservation. Illustrations and measurements (mean \pm standard error) were made on preserved material using a binocular microscope with an eyepiece micrometer and FSA 25 PE drawing tube. The photographs were taken with a scanning electron microscope (SEM) operated at $20 \mathrm{kV}$.

Terminology used for descriptions of the larvae follows Hartley (1961) and Rotheray (1993), including the term "mandibular lobes", although the structures are probably of maxillary origin. The positions of the sensilla were numbered sequentially from the dorsal to the ventral surface for each segment (Rotheray, 1991).

The cephalopharyngeal skeleton was removed from the leading ventral edge of the interior of the puparia, and was then placed in warm potassium hydroxide $(\mathrm{KOH})$ for 3-4 min. Finally it was washed in distilled water and preserved in glycerine until examination. Morphological terminology of this stage follows Whittington (1994) and Hartley (1963).
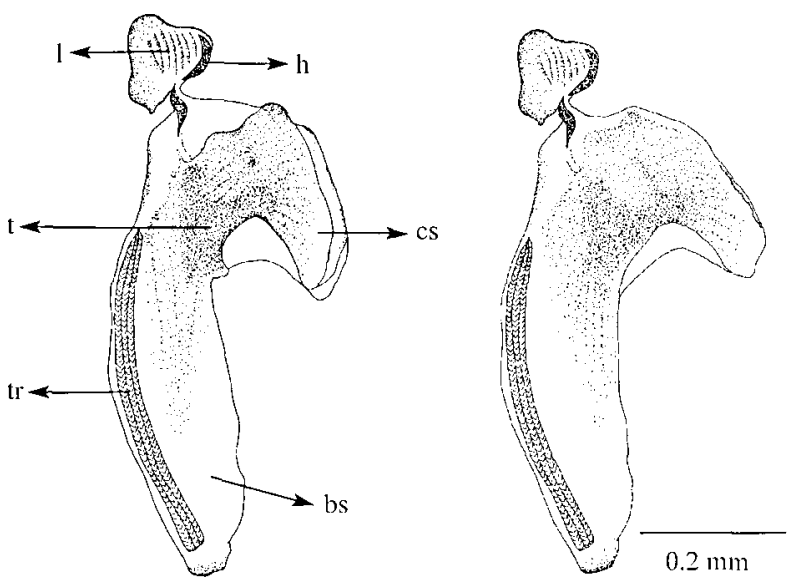

Figs 2, 3: Cephalopharyngeal skeleton, lateral view. 2 - $S$. flaviventris; $3-S$. pipiens. Lettering: h - mouth-hooks; 1 "mandibular lobes"; t - tentorium; cs - clypeal sclerites; bs basal sclerites; $\mathrm{tr}$ - T-ridges.
Voucher specimens of adult and immature stages of $S$. pipiens and S. flaviventris are stored in the Entomological Collection of Alicante University and one larva of $S$. flaviventris in the National Museum of Scotland, Edinburgh.

\section{RESULTS}

\section{Description of immatures stages of Syritta flaviventris}

\section{Third larval instar (L3)}

Length 8-10 mm, maximum width $1.5-2 \mathrm{~mm}(\mathrm{n}=4)$. Overall appearance: A short-tailed larva with internal mouth-hooks, bearing three conspicuous pairs of fleshy lappets located before the posterior end of the larva (Fig. 4). Subcylindrical in cross-section with a flattened ventral surface, truncate anteriorly, and slightly tapering posteriorly. Cuticle translucent when alive, cream to off-white after fixation. Hind gut green throughout the translucent body in actively feeding individuals, otherwise hind gut obscured by white adipose tissue. Dorsal body surface coated in short and fine pubescence backwardly directed, longer and slightly sclerotised on the terminal body segments. Setae on ventral suface are shorter except for the anal segment (hind end).

HEAD. Mouth-hooks (h) and "mandibular lobes" (l) internal [mouthparts of the saprophagous type of Roberts (1970)]. Antenno-maxillary organs well developed. Cephalopharyngeal skeleton: Mouth-hook crescentshaped, dorsally slightly angular, not sharply pointed nor toothed (Fig. 2); "mandibular lobes" small, about as wide as mouthhook length, ribbed, with combs of filaments on inner ridges; parastomal bar not visible; pharyngeal sclerite with posterior projections; clypeal sclerites (cs) connected by dorsal bridge; these sclerites are short and strongly pigmented medially and on tentorium (t); basal sclerite (bs) long, narrow and slightly sclerotised. Tridges (tr) with ribbed cibarial filter.

Thorax. Lateral lips rounded and well developed (in profile projecting forward from the anterior part of the prothorax) and covered with short and fine setae at base and longer and conspicuous spicules at tip. Anterior fold on dorsal surface of prothorax with longitudinal grooves 


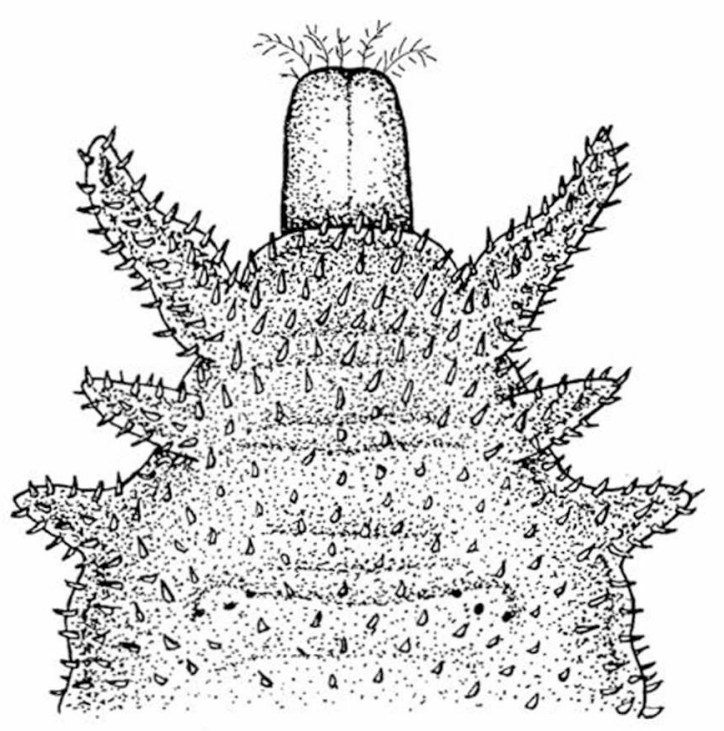

$1 \mathrm{~mm}$

Fig. 4. S. flaviventris, anal segment of puparium in dorsal view showing three pairs of lappets.

and a narrow band $(<40 \%$ of anterior fold) of densely aggregated, backwardly directed, sclerotised spicules which become progressively shorter posteriorly. Dorsal surface of prothorax with anterior respiratory process weakly sclerotised, short and narrow. Lateral margin of prothorax (P) with two paired patches of sclerotised spicules arranged as follows: A group of 7 just anterior to 4 th sensillum of mesothorax (Ms) and another prothoracic group of 12 spicules is located in front of 5th sensillum of mesothorax (Fig. 1). Mesothorax bearing well developed prolegs with about 20 crochets. Ventral surface of metathorax (Mt) with two little patches bearing very small crochets in the position homologous to the mesothoracic prolegs.

ABDomen. Primordia of pupal spiracles distinct on dorsal surface of first abdominal segment. Ventral prolegs (Pr) small, 6 abdominal pairs on segments 1-6. Each proleg with 2 or 3 rows of apically brown crochets: 5 or 6 primary, 4 or 5 secondary and some tertiary. Crochets in anterior row slightly bigger than those posterior. Crochets are directed posteriorly except on the last abdominal segment where some are anteriorly directed. Anal segment with three pairs of fleshy lappets, last pair bigger than the anterior ones (Fig. 4).

POSTERIOR RESPIRATORY PROCESS (PRP) (STIGMATOPHORE). Length $1.6 \pm 0.03 \mathrm{~mm}$; width at base $0.5 \pm 0.01 \mathrm{~mm}$, at tip $0.38 \pm 0.009 \mathrm{~mm}(\mathrm{n}=4)$. Lustrous, brown in colour, with six spiracular slits arranged around two central scars. Spiracular slits with a clearly sinuous shape as in Fig. 6. Four pairs of spiracular setae with at least five branches (Fig. 5).

Chaetotaxy. Prothorax with 12 pairs of sensilla; mesothorax and metathorax with 9 pairs each; abdominal segments 1-7 with 11 pairs; hind end with 8 pairs (Fig. 1).

PUPARIUM. Length including posterior respiratory process $6.5 \mathrm{~mm}$, maximum width $2.5 \mathrm{~mm}(\mathrm{n}=3)$. Subcylindrical in cross-section. Anterior extreme rounded, tapered posteriorly and flattened slightly ventrally (Fig. 8). Integument rough, with segmentation of larvae persisting as transverse folds and wrinkles. Ventral surface with prolegs visible on mesothorax and first 6 abdominal segments. Dorsally, the two thoracic respiratory processes protrude on the upper half of the operculum (Fig. 10). These processes are subconical structures, swollen and lobulated apically (Fig. 12). Basal part of the thoracic respiratory processes nodulated on the two basal thirds, with a small smooth area just below the swollen apex. Lobulated area presents numerous disc-shaped spiracular openings, distributed irregularly on the surface (Fig. 14). Each disc has from 2 to 6 oval apertures.

\section{Life history}

Adults of Syritta species were repeatedly observed flying around the platyclades of O. maxima. Examination of these platyclades revealed that the larvae and puparia were confined to decaying platyclades.

The life cycle is completed inside decaying platyclades that characteristically occur on the branches of $O$. maxima, and also on detached and fallen platyclades. Puparia were always found inside old dried platyclades where the decaying process was complete.

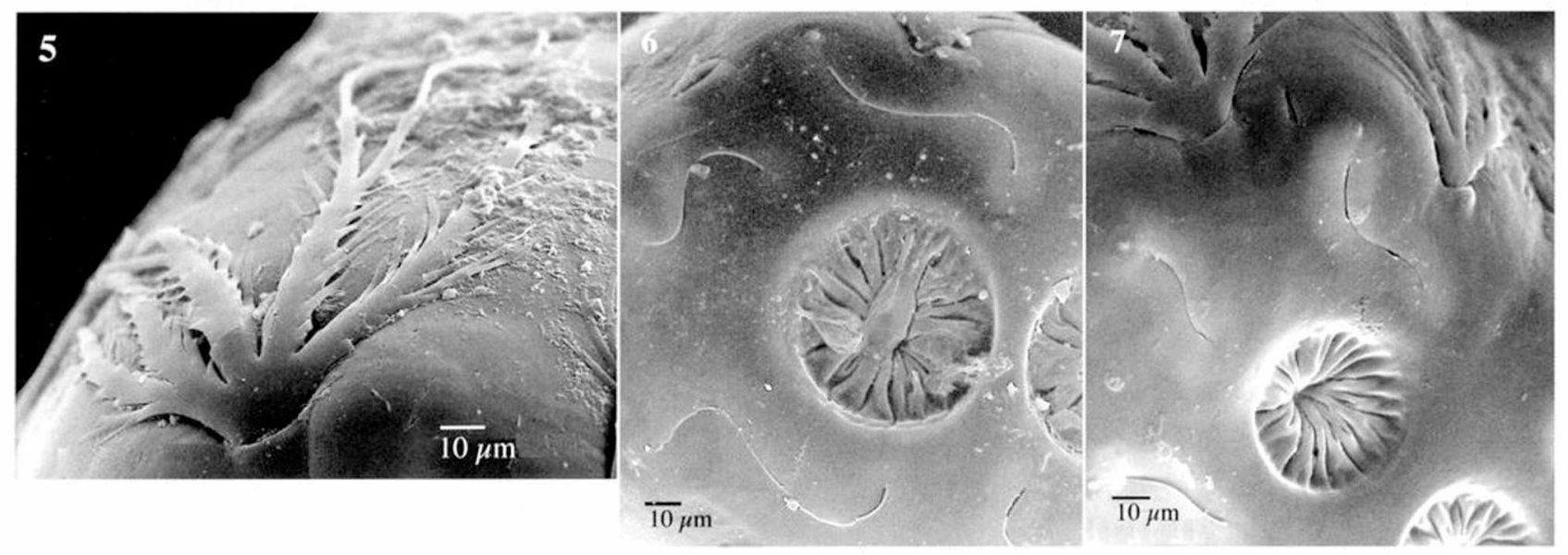

Figs 5-7. 5, 6: S. flaviventris. 5 - spiracular setae of the posterior respiratory process; 6 - spiracular slits of the posterior respiratory process. $7-S$. pipiens, spiracular slits of the posterior respiratory process. 

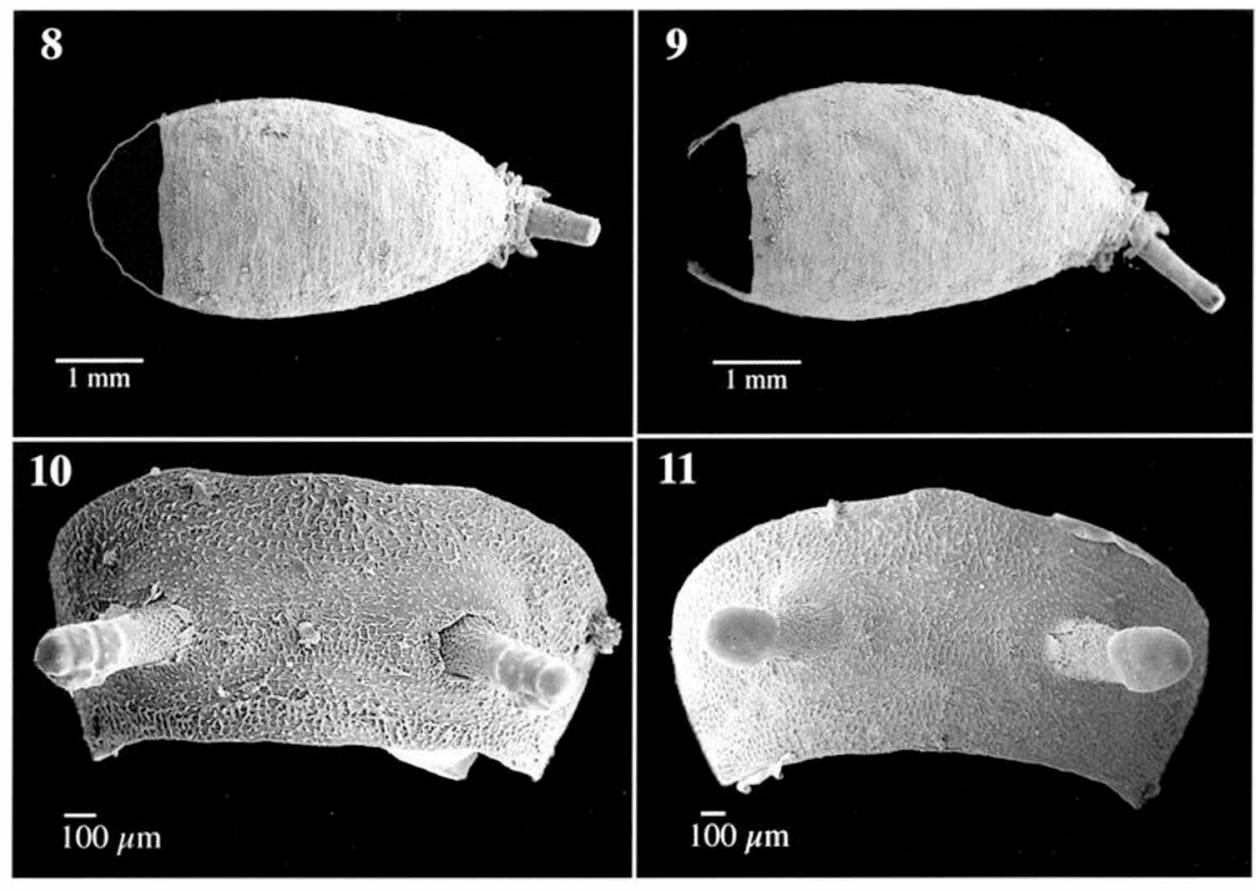

Figs 8-11.8,9-puparia in dorsal view. 8 -S. flaviventris; 9 -S. pipiens. 10,11-operculum with pupal respiratory process. 10 S. flaviventris; $11-$ S. pipiens.

Generally, damaged platyclades shelter numerous larvae of S. pipens together with other saprophagous larvae of Eumerus purpurariae and S. flaviventris with larvae of the latter only occasionally observed (Fig. 16).

Adults of $S$. pipiens could be found throughout the year. Larvae and puparia of this species were found from early winter to summer (December to August) (Fig. 16). The puparium period was $8-11$ days $(n=20)$.
The imagines of $S$. flaviventris were scarce and observed only from February to March. Larvae and puparia of this species were found during early winter (January and February) (Fig. 16). Pupal period was $8-10$ days $(n=$ 3).

\section{DISCUSSION}

The co-occurrence of larvae of Syritta with larvae of other hoverflies has also been observed in various other

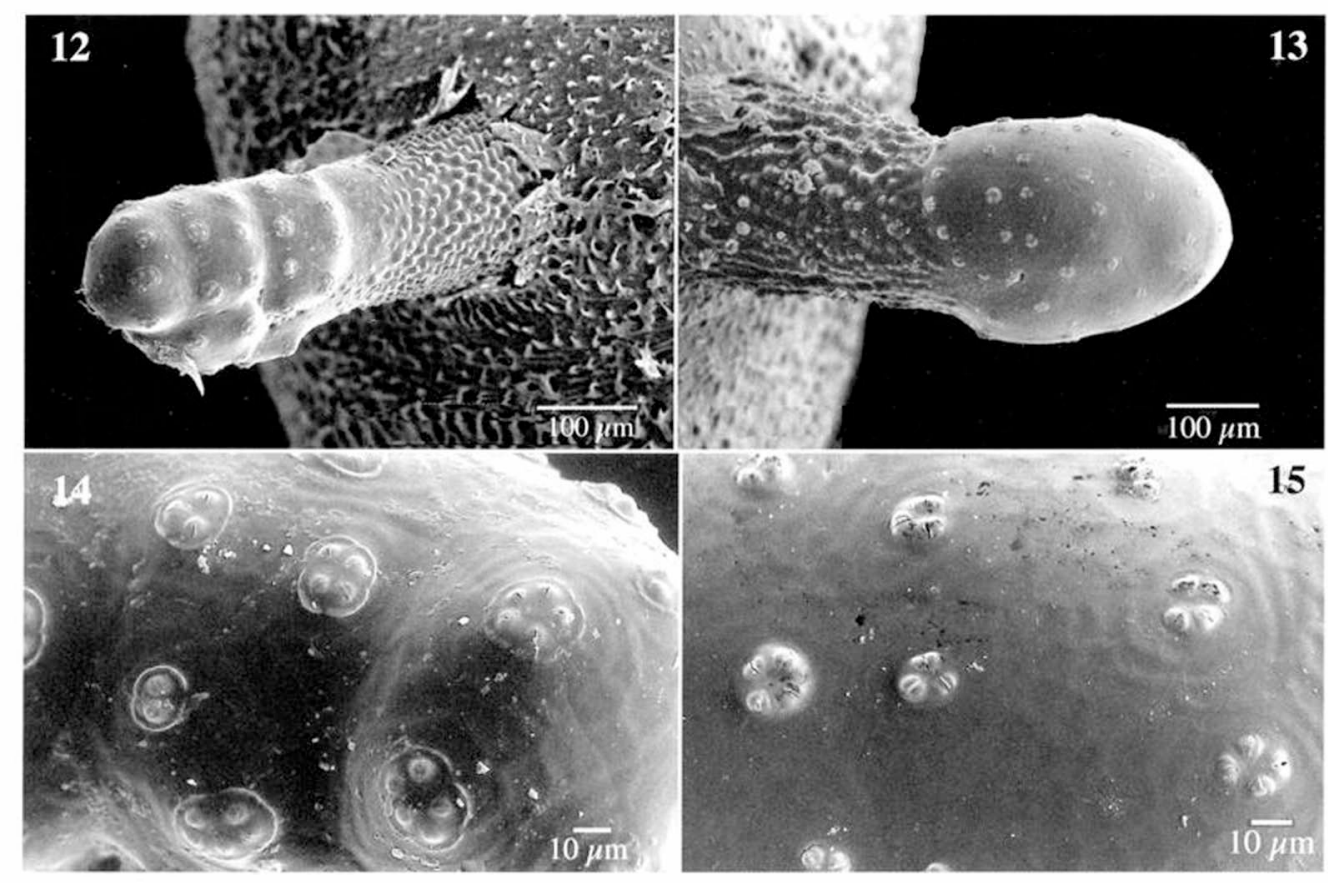

Figs 12-15. 12, 13 -thoracic respiratory process of puparium. 12 -S. flaviventris; 13 - S. pipiens. 14, 15-spiracular openings. 14 -S. flaviventris; $15-$ S. pipiens. 


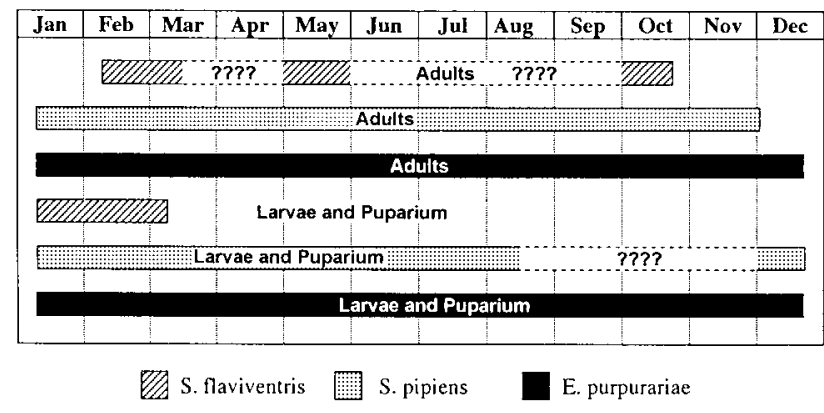

Fig. 16. Phenology of syrphids breeding in O. maxima.

decaying materials. Hodson (1931) reported that S. pipiens appears occasionally with Eumerus tuberculatus Rondani, 1857 in decayed narcissus bulbs, and most recently Pérez-Bañón \& Marcos-García (1998) found S. pipiens together with E. purpurariae in decaying platyclades of O. maxima. Co-occurrence has also been demonstrated with phytophagous syrphid larvae: Brunel \& Cadou (1994) found one larva of S. pipens on an artichoke root attacked by Cheilosia vulpina, probably using the rotting plant debris as food source.

Rotheray (1993) provides a key to European hoverfly genera based on third-instar larvae. In this key the identification characters for the genus Syritta are based exclusively on larvae of $S$. pipens. These morphological characters (prolegs small with 5 or 6 primary crochets arranged as a transverse row across the segment; anal segment with 3 pairs of lappets, the first two pairs equal in length and third pair longest at tip) are shared by the larvae of $S$. flaviventris.

As could be expected, the larvae of S. flaviventris and $S$. pipens show striking similarities. However, close examination revealed slight but obvious differences between both species. Therefore, the larvae of the genus Syritta may be distinguished according to the characteristics summarized in Table 1: Ornamentation of dorsal body surface and shape of the slits on posterior respiratory process.
The main diagnostic characters of the puparium are: (1) shape of thoracic respiratory processes, (2) ornamentation of thoracic respiratory processes, and (3) shape of spiracular openings of thoracic respiratory processes (Table 1).

The morphology of the cephalopharyngeal skeleton of S. flaviventris is very similar to S. pipens (Figs 2, 3), both species have well developed ventral pharyngeal ridges. The ventral pharyngeal ridges select the appropriate food particle size, permitting partial digestion before swallowing of the particles and increasing efficiency of food utilisation by its concentration (Roberts, 1969). Larvae possessing pharyngeal ridges are essentially particle feeders, reducing the amount of non-nutritious liquid ingested and concentrating food (consisting of a suspension of bacteria, protozoa, fungal spores and yeast) by sieving (Dowding, 1967). In conclusion, the morphological study together with the rearing data of S. flaviventris reveal saprophagous feeding habits within decaying platyclades of Opuntia cacti.

Hartley (1963) reported that differences in diet between taxa are mainly reflected by differences in relative proportions and sclerotisation of the sclerites of the cephalopharyngeal skeleton. Since clear morphological differences between the cephalopharyngeal skeleton of $S$. flaviventris and S. pipiens are lacking, this may indicate that there are no differences in diet between these two taxa. The fact that the larvae of both species were found breeding together supports this hypothesis. Moreover, prickly pear cacti were not introduced into the distribution area of S. flaviventris until the 16 th century, and the relationship between this host plant and $S$. flaviventris larvae should be a secondary adaptation. Therefore, the larvae of $S$. flaviventris may be found in other kinds of decaying matter similar to the breeding media employed by S. pipiens.

ACKNOWLEDGEMENTS. We thank G. Rotheray for critically reviewing an earlier draft of this manuscript. The illustrations were kindly produced by M. Luz Roca. Financial support was provided by the Generalitat Valenciana (GV-C-RN-12-069/96) and the Ministerio de Educación y Ciencia (PB 96/01413).

TABLE 1. Differences between the third stage larva and puparium of $S$. flaviventris and S. pipiens.

\begin{tabular}{|c|c|c|}
\hline Character & S. flaviventris & S. pipiens \\
\hline \multicolumn{3}{|l|}{ Larva } \\
\hline Dorsal body surface (ornamentation) & $\begin{array}{l}\text { Covered with short and fine pubescence } \\
\text { backwardly directed, longer and slightly } \\
\text { sclerotised on the last segments }\end{array}$ & $\begin{array}{l}\text { Covered with short and fine } \\
\text { pubescence backwardly directed }\end{array}$ \\
\hline $\begin{array}{l}\text { Spiracular slits (posterior respiratory } \\
\text { process) }\end{array}$ & Clearly sinusoidal (Fig. 6) & Only slightly sinusoidal (Fig. 7) \\
\hline \multicolumn{3}{|l|}{ Puparium } \\
\hline $\begin{array}{l}\text { Thoracic respiratory processes } \\
\text { shape }\end{array}$ & $\begin{array}{l}\text { Swollen apically with lobulated profile } \\
\text { (Fig. 12) }\end{array}$ & $\begin{array}{l}\text { Swollen apically with smooth profile } \\
\text { (Fig. 13) }\end{array}$ \\
\hline $\begin{array}{l}\text { Ornamentation of thoracic } \\
\text { respiratory processes }\end{array}$ & $\begin{array}{l}\text { Nodulated but with a smooth area just below } \\
\text { the swollen area (Fig. 12) }\end{array}$ & $\begin{array}{l}\text { Nodulated from base to just below the } \\
\text { swollen area (Fig. 13) }\end{array}$ \\
\hline $\begin{array}{l}\text { Spiracular openings of thoracic } \\
\text { respiratory processes }\end{array}$ & $\begin{array}{l}\text { Spiracular openings on a disc-shaped base } \\
\text { (Fig. 14) }\end{array}$ & $\begin{array}{l}\text { Spiracular openings directly on the } \\
\text { surface of swollen area (Fig. 15) }\end{array}$ \\
\hline
\end{tabular}




\section{REFERENCES}

Bugbee R.E. \& Reigel A. 1945: The Cactus Moth, Melitara dentata (Grote), and its effect on Opuntia macrorrhiza in Western Kansas. Am. Midl. Nat. 33: 117-127.

Brunel E. \& CAdou D. 1994: Syrphid larvae (Diptera: Syrphidae) mining the roots of artichoke (Cynara scolymus L.) in Brittany. Dipterists Digest 1: 69-71.

DiRICkX H.G. 1994: Atlas des Diptères syrphides de la région méditerranéenne. Institut Royal des Sciences Naturelles de Belgique, Bruxelles, $317 \mathrm{pp}$.

DiRICKX H.G. 1998: Catalogue synonymique et géographique des Syrphidae (Diptera) de la région afrotropicale. Museum d'Histoire Naturelle, Genève, $187 \mathrm{pp}$.

Dixon T.J. 1960: Key to and descriptions of the third instar larvae of some species of Syrphidae (Diptera) occurring in Britain. Trans. R. Entomol. Soc. Lond. 112: 345-379.

Dodd A.P. 1940: The Biological Campaign Against PricklyPear. Commonwealth Prickly Pear Board, Brisbane, 177 pp.

Dowding V.M. 1967: The function and ecological significance of the pharyngeal ridges occurring in the larvae of some cyclorrhaphous Diptera. Parasitology 57: 371-388.

GILbert F.S. 1993: Hoverflies. Naturalists' Handbooks 5. Cambridge University Press, Cambridge, $67 \mathrm{pp}$.

HaRTLEY J.C. 1961: A taxonomic account of the larvae of some British Syrphidae. Proc. R. Entomol. Soc. Lond. 33: 505-573.

HARTLEY J.C. 1963: The cephalopharyngeal apparatus of Syrphid larvae and its relationships to other Diptera. Proc. Zool. Soc. Lond. 141: 261-280.

HeIss E.M. 1938: A classification of the larvae and puparia of the Syrphidae of Illinois exclusive of aquatic forms. Illinois Biol. Monogr. 36: 1-142.

Hodson W.E.H. 1931: A comparison of the immature stages of Eumerus tuberculatus Rond. and Syritta pipiens Lin. (Syrphidae). Bull. Entomol. Res. 22: 55-58.

KrÜGER F. 1926: Biologie und Morphologie einiger Syrphidenlarven. Z. Morphol. Ökol. Tiere 6: 83-149.

LUNDBECK W. 1916: Lonchopteridae, Syrphidae. Diptera Danica 5. G.E.C. Gad, Copenhagen, 591 pp.

MAIER C.T. 1982: Larval habitat and mate-seeking sites of flower flies (Diptera: Syrphidae: Eristalinae). Proc. Entomol. Soc. Wash. 84: 603-609.

Maldonado Capriles J. \& Berrios A. 1977: The immature stages of Copestylum vacuum (F.) (Diptera: Syrphidae). A new record for Puerto Rico. J. Agr. Univ. Puerto Rico 61: 395-399.

PeCK L.V. 1988: Family Syrphidae. In Soós Á. (ed.): Catalogue of Palaeartic Diptera. Vol 8. Syrphidae-Conopidae. Akademiai Kiadó, Budapest, pp. 11-230.

Pérez-Bañón C. \& Marcos-Garcia M.A. 1998: Life history and description of the immature stages of Eumerus purpurariae (Diptera: Syrphidae) developing in Opuntia maxima. Eur. $J$. Entomol. 95: 373-382.

RYCKMAN R.E. \& AMEs C.T. 1953: Insects reared from cacti in Arizona. Pan-Pac. Entomol. 60: 326-331.

ROBERTS M.J. 1969: The feeding habits of higher dipteran larvae. Entomologist 102: 99-106.

ROBERTS M.J. 1970: The structure of the mouthparts of syrphid larvae (Diptera) in relation to feeding habits. Acta Zool. (Stockholm) 51: 43-65.

RotherAy G.E. 1991: Larval stages of 17 rare and poorly known British hoverflies (Diptera: Syrphidae). J. Nat. Hist. 25: 945-969.

RotherAy G.E. 1993: Colour guide to hoverfly larvae (Diptera, Syrphidae) in Britain and Europe. Dipterist Digest No. 9. Derek Whiteley, Sheffield, $156 \mathrm{pp}$.

SPEIGHT M.C.D. 1986: Portevinia maculata (Fal.): last instar larva and puparium, with notes on the relationship between this hoverfly and its larval host-plant, Allium ursinum (Diptera, Syrphidae). Nouv. Rev. Entomol. (N.S.) 3: 37-43.

Telford H.S. 1973: The Syrphidae of Puerto Rico. J. Agr. Univ. Puerto Rico 57: 217-246.

Tiompson F.C., Vockeroth J.R. \& Sedman Y.S. 1976: Family Syrphidae. A Catalogue of the Diptera of the America South of the United States. Vol 46. Museu de Zoologia, Universidade de Sao Paulo, São Paulo, 195 pp.

THOMpSON F.C. \& Vockeroth J.R. 1989: Family Syrphidae. In Evenhuis N.L. (ed.): Catalog of the Diptera of the Australasian and Oceanian Regions. Bishop Museum \& E.J. Brill, Honolulu, pp. 437-458.

WallaCe J.B. \& LAVAlLEE A.G. 1973: Immature stages of Milesiinae (Syrphidae) 1: Cheilosia pallipes and Volucella apicalis. J. Ga Entomol. Soc. 8: 187-194.

WhitTington A.E. 1994: Descriptions of the puparia of three Graptomyza species (Diptera Syrphidae), with comments on probable larval biology. Trop. Zool. 7: 57-65.

Received January 26, 1999; accepted June 14, 1999 